\title{
Integrating therapies for surgical adult soft tissue sarcoma patients
}

\author{
Daniel P. Milgrom ${ }^{1}$, Amikar Sehdev ${ }^{2}$, Joshua K. Kays ${ }^{1}$, Leonidas G. Koniaris ${ }^{1}$ \\ ${ }^{1}$ Department of Surgery, ${ }^{2}$ Division of Medical Oncology, Indiana University School of Medicine, Indianapolis, IN 46202, USA \\ Contributions: (I) Conception and design: All authors; (II) Administrative support: All authors; (III) Provision of study materials or patients: All \\ authors; (IV) Collection and assembly of data: All authors; (V) Data analysis and interpretation: All authors; (VI) Manuscript writing: All authors; (VII) \\ Final approval of manuscript: All authors. \\ Correspondence to: Leonidas G. Koniaris, MD. Department of Surgery, EH 511 SGEN, Indianapolis, IN 46202, USA. Email: 1koniari@iu.edu.
}

\begin{abstract}
Sarcomas are an uncommon group of over 50 different individual histological malignancies arising from mesenchymal (non-epithelial or connective) tissues. Overall, they constitute $1 \%$ of human malignancies with an annual incidence rate of fewer than 5 patients per million. Sarcoma may arise from any mesenchymal cell lineages including fat, muscle, or other connective tissues. Due to the rarity of these groups of malignancies, many subtypes were, and still today, are managed as a single entity. This review focused on soft tissue sarcomas with an emphasis on how to integrate therapies for patients with this rare disorder. The role for surgical resection in cure and palliation as well as the relative benefits of adjuvant therapies such as chemotherapy and radiation therapy are discussed.
\end{abstract}

Keywords: Gastrointestinal stromal tumors (GIST); stromal; liposarcoma; malignant fibrohistiosarcoma (MFH); sarcoma; disparities

Received: 16 October 2018; Accepted: 22 October 2018; Published: 02 November 2018.

doi: $10.21037 / \operatorname{tgh} .2018 .10 .12$

View this article at: http://dx.doi.org/10.21037/tgh.2018.10.12

\section{Introduction}

Sarcomas are an extremely uncommon group of malignancies arising from mesenchymal (non-epithelial or connective) tissues. Overall, they constitute $1 \%$ of human malignancies with an annual incidence rate of fewer than 5 patients per million $(1,2)$. Sarcoma may arise from any mesenchymal cell lineages including fat, muscle, or connective tissue. Overall, over 50 different individual histological sarcoma subtypes have been described. Due to the rarity of these groups of malignancies, many subtypes were, and still today to a large extent, are managed as a single entity.

Overall patients with soft tissue sarcoma (STS) will present with either localized or metastatic disease. Approaches for localized disease generally primarily focus on the use of surgical extirpation to remove the tumor; ideally with a margin-negative resection, usually without lymph node resection. Such surgeries can result in significant overall cure rates. In the setting of localized STS, radiation therapy may serve as an adjunct for local control in the setting of close margins with high-grade disease (3). Based upon tumor type and grade, chemotherapy is an additional adjunct that remains somewhat controversial for resectable disease depending upon the specific tumor type. Chemotherapy, however, is certainly beneficial for some subtypes and, like radiation therapy, most likely beneficial for higher-grade tumors. The role of chemotherapy, nonetheless, although clearly beneficial for some high-grade STS subtypes, remains somewhat controversial as both phase II and populationbased studies demonstrate minimal to no benefit in overall survival on top of surgery and no improvement in survival for many subtypes with metastatic disease (4).

Although the role of adjuvant therapies is modest in the management of STS, over half of all STS patients will survive beyond 5-years following presentation. As targeted therapies have been introduced, survival rates have dramatically improved for certain subtypes, such as GIST. For other STS types outcomes have not changed (5-7). This review focuses on integrating therapies around the treatment of the STS patient with a focus on overall management and surgical considerations. 


\section{Presentation}

STS generally present as a painless mass that may be slow growing or rapidly expanding. The differential diagnosis for masses noted by exam or cross-sectional imaging is broad and can include benign tumors, adenocarcinomas, and lymphomas. STS arising in the head and neck or extremity usually present with tumors under $5 \mathrm{~cm}$ in size as the patients' frequently notice and seek attention for new painless masses (8). However, diagnosis can be initially delayed due to the concealed anatomic location of the mass, such as within the abdomen, thorax or retroperitoneum. Tumors in these areas can develop extremely large in size and may be diagnosed following cross-sectional imaging frequently for vague symptoms, such as pain, impaired function of the invaded organs or incidentally discovered for other reasons. As a general rule, STS arising in the trunk with greater invasive or desmoplastic biology will present earlier and with smaller size as adjacent organ invasion may cause obstruction of bowel, ureter or other hollow viscus structures $(9,10)$. Of truncal sarcomas, thoracic STS tend to present at the smallest size, as these masses frequently will cause organ compression resulting in dyspnea or cardiac function problems. For both abdominal and retroperitoneal tumors, larger sizes are more common, as these locations can be associated with minimal symptoms even at very large sizes. Tumors arising in the retroperitoneum frequently are the least symptomatic and present on average with the largest tumor sizes. In fact, over two-thirds of retroperitoneal tumors present over $10 \mathrm{~cm}$ in diameter with 20-30 cm masses not being infrequent $(11,12)$.

\section{STS types by location}

Regarding distribution, STS in adults arise most commonly in the trunk or retroperitoneum (62\%), extremity $(30 \%)$ or head and neck area (7\%). Among STS, the most common types are leiomyosarcoma (LMS) and gastrointestinal stromal tumors (GIST) (together accounting for $40 \%$ of STS), followed by undifferentiated pleomorphic sarcoma/ malignant fibrohistiosarcoma (MFH; 30\%), liposarcoma (20\%), fibrosarcoma (6\%) and other tumor types (4\%) $(1,2,11,13)$. In head and neck tumors, MFH is most common sarcoma $(8,14)$. In the trunk, LMS/GIST are the most common while in the retroperitoneum, liposarcoma is the most common (13).

In adults, sarcoma incidence has been noted to be increasing in the population with an incidence of
$30-35$ cases per 1,000,000 population. This increase is likely, in part, related to the increasing utilization of cross-sectional imaging revealing incidental slow-growing masses. Risk of developing sarcoma is more common after age 50 years with a stable incidence being observed after that age $(2,10,13)$.

\section{Is there a need for tissue diagnosis?}

The great variety of tumor types and the potential for different optimal therapeutic approaches support the routine biopsy to obtain a clear histologic diagnosis prior to initiating treatment. Differential diagnosis may, based upon cross-sectional imaging information, include inflammatory, benign, locally aggressive tumors, STS and other malignancies. Biopsy, either obtained by core-needle or open techniques may prevent surgery in instances where a mass may not represent sarcoma or may allow initiation of alternative therapies such as a targeted neoadjuvant approach potentially as part of a clinical trial. That being said, in instances where the diagnosis can be accurately ascertained by cross-sectional imaging, where severe symptoms exist or if the differential includes tumors that would all benefit from resection, then a preoperative tissue diagnosis may not be necessary prior to resection. Examples of this would include large retroperitoneal masses, particularly those with a density consistent with fat, hypervascular gastric masses consistent with GIST, or instances of a likely sarcoma with intestinal obstruction. Care should be exercised if resection is planned without a prior tissue diagnosis, as conditions such as lymphoma may mimic those of sarcoma in many locations including the pelvis, groin and retroperitoneum (15-18).

\section{Biopsy approach}

For patients where a core or open biopsy is planned, consideration as to how to approach the tumor biopsy is important. Generally, regardless if an open or core biopsy is planned, the tract should be placed in such a way as it might be excised during the definitive resection to both hopefully optimize local control and prevent tumor seeding (19).

Some authors prefer a core biopsy to make a diagnosis of STS. This certainly is useful for cases of intestinal sarcoma where a diagnosis may be unclear or targeted neoadjuvant chemotherapy for GIST planned. Core biopsy is also an excellent first approach in settings where a local recurrence of disease or metastases is suspected. Furthermore, if preoperative concerns regarding subjecting a patient to 
open biopsy due to their overall health, comorbidities, or tumor location may also justify a core biopsy. In such cases a core biopsy may allow a rapid diagnosis of recurrence and allow implementation of a variety of non-surgical therapies if warranted (16,20-22). Many clinicians prefer an open biopsy to a core biopsy especially in locations where an open biopsy can be easily and safely obtained. This is mainly because it can be hard to make the diagnosis on core biopsy due to large amount of necrotic tissue. Furthermore, the limited tissue provided by a core biopsy may miss highergrade components of the tumor. Nonetheless, a core biopsy may be used as a first attempt to obtaining a diagnosis if it may be obtained expediently. The reader is cautioned, however, to recognize that if obtaining a core biopsy might ultimately delay diagnosis and implementation of care, consideration to immediately proceeding to a definitive open biopsy may be optimal (23-25).

In the extremity and more superficial areas of the trunk, biopsy for patients with a new soft tissue mass is generally best accomplished by open biopsy. Considerations regarding the incision would be to place it in such a way as to allow easy re-excision of the mass during definitive care. Generally this is done by making the incision along the long axis of an extremity, overlying the mass of interest. Transverse incisions over the extremity may be suboptimal as they may be difficult to fully re-excise and may complicate subsequent incisional closure and healing due to blood-flow disruption. Usually biopsies are planned as incisional rather than excisional, as total removal of a mass at initial biopsy may make subsequent margin-negative surgery difficult to achieve. Nonetheless, excisional biopsy is reasonable and may be a better option for smaller tumors such as those under $5 \mathrm{~cm}$. These smaller masses frequently will prove not to be malignant and may allow a patient to not undergo a second procedure $(25,26)$.

\section{Localized disease: the principles of surgical resection}

For STS, surgery has been recognized as the main therapy for patients, and one that can provide the most significant chance for palliation, long-term survival and the only therapy associated with cure. Although a multidisciplinary approach is necessary in most cases, the management of resectable STS should have key input from the surgeon due to the critical role for surgery in optimizing the pre-operative planning and approach to resection $(3,12,14,25,27)$.

Theoretical operative objectives for all STS are similar and focus on obtaining a margin-negative resection generally without need for lymphadenectomy. Many experts suggest that 1-2 cm negative margins or inclusion of an additional plane of uninvolved tissue should be the goal of surgery (3,28-30). However, some studies suggest that a margin-negative resection, regardless of margin distance, provides similar local control rates (31). Close margins may be encountered particularly in large truncal tumors as the ability to provide a margin-negative resection is complicated by the presence of adjacent critical anatomical structures necessitating a microscopic (R1) or macroscopic (R2) positive resection. Furthermore, R1 resections may still be curative as the patients undergoing $\mathrm{R} 1$ resection frequently do not demonstrate recurrent disease except when tumor characteristics are unfavorable (such as, high grade tumors) $(3,8,14,27,29)$. In such cases, local recurrence rate can be high, ranging from $30 \%$ in $\mathrm{R} 1$ resection vs. $10 \%$ in $\mathrm{R} 0$ resections. Consideration should be given for adjuvant radiotherapy in cases of $\mathrm{R} 1$ resection, particularly with high grade malignancies $(3,27,32)$.

Prognosis and the benefit of adjuvant treatment are greatly influenced by the final margin status of a resection. Prognosis following resection will be impacted by tumor type, but also heavily influenced by a number of additional considerations including grade, size and location (truncal/ retroperitoneal versus extremity). Patient considerations include nutritional status, comorbidities and overall performance status. Therefore, in patients presenting with a painless mass or a large truncal mass the diagnosis of STS must be considered $(3,12,14,26,27,29,33)$.

\section{Surgical approach by location}

\section{In localized extremity tumors}

A multimodal approach that attempts to avoid extremity amputation has been pursued since the critical work of Rosenberg and coworkers (30). Approaches to extremity sarcoma with limb-sparing resections tolerating R1 or R2 resections if critical structures like nerves are involved with the use of adjuvant radiation and possibly chemotherapy can obtain excellent local control rates in some cases exceeding $90 \%$. Patient survival following limb-preservation actually appears to exceed that associated with amputation, and thoughtful limb-preserving resection can be associated with excellent functional status with no apparent defect in the majority of patients $(34,35)$. Nonetheless, complications of resection and radiation can lead to significant problems in the extremity including severe edema, chronic wound formation and impaired functional capacity (36-38). 


\section{Truncal sarcoma}

Outcome for STS of the trunk are generally poorer than those of the extremity due to both more advanced stage at presentation and troublesome location that can make margin-negative extirpation difficult. Technical issues include dealing with the attainment of larger size and increased difficulty in obtaining negative margins due to invasion or intricate involvement with a number of vital structures that must be preserved. Local recurrence rates exceeding $30 \%$ may be expected and, in cases of very large, poor-prognosis sarcomas involving numerous critical structures, recurrence may be unavoidable and surgery is largely a palliative undertaking (39). Postoperative complications to surgical extirpation are similar to those encountered around similar surgeries and the organs involved. Surgical complications can include bowel obstruction, nerve damage including asthenia, leg weakness, and impotence. Use of adjuvant or neoadjuvant chemotherapy or radiation therapy generally is associated with more complications including enteritis, peripheral neuropathy and scarring $(4,25,32,36,40)$.

\section{Adjacent organ invasion and oligometastatic disease}

Surgical extirpation of STS may involve the resection of organs that become invaded or compromised. The capacity to do so safely and preserve organ function remains a critical component of sarcoma surgery and may require resection of any combination of involved organs. As a general rule, facility of the surgical team to perform each organ-specific surgery will be required. The objectives in such scenarios remains obtaining a margin-negative resection, thus organpreserving approaches are critical $(25,41,42)$.

\section{Importance of specialty centers to optimize patient outcomes}

Optimizing care for sarcoma patients may best be done at centers with experience in their management, both in the operating room and with adjuvant therapies. Increased recurrence rates have been reported in patients who were referred to centers with expertise in sarcoma after definitive operation. Mortality rates and amputation rates have been demonstrated to be lower at specialty centers (43). Specialty centers allow for multidisciplinary teams, as well as enrollment in clinical studies (12,43-45). Furthermore, preoperative planning with an experienced plastic surgeon can lead to improved cosmetic and functional outcomes (46). Additional considerations regarding reconstruction are well described by Hadad et al. in this special issue (47).

\section{Therapeutic considerations: balancing surgery with adjuvant therapies}

When patients present with sarcoma, the mainstay therapy remains surgery with a goal of providing a margin-negative resection of the malignancy. In instances where the tumor is not amendable to complete surgical extirpation, particularly in instances of high-grade malignancy, the use of adjuvant therapies including radiation therapy and chemotherapy should be considered.

\section{Radiation}

The role of radiation therapy (RT) for extremity sarcoma is well established as part of an integrated, limb-preserving approach to extremity sarcoma. Doses approaching 60 cGy and more are generally well tolerated and associated with excellent local control rates. The introduction of radiation and advanced reconstructive techniques has decreased limb amputation rates without sacrificing overall survival $(30,48)$. While radiation can be performed either preoperatively or postoperatively with equivalent disease control, preoperative radiation is associated with improved wound healing and less late-term morbidity (49). Complications of RT in the extremity include edema, failure of wound healing and increased risk of fracture. Care must be used in STS patients to minimize radiation to bones and risk of pathologic fracture $(36,37)$.

The role of RT for the treatment of STS of the abdomen, chest and retroperitoneum is less well defined and must balance toxicity associated with RT, the intrinsic inability of solid organs to tolerate RT, and relatively high RT doses required to improve local control. RT dose is limited by sensitivities of adjacent normal tissues such as bowel, kidney, liver, and spinal cord. Similar to the treatment of extremity sarcoma, preoperative RT is preferred. New techniques are being developed to limit toxicity by sparing normal tissue $(27,32,39)$.

\section{Role of chemotherapy}

Early studies suggested soft tissue sarcoma prognosis was more dependent upon location and grade than sarcoma type. Subsequent examination, however, including both population-based analyses and molecular analyses of tumor mutations, have clarified that adjuvant chemotherapy for sarcoma and subsequent prognosis may be critically dependent upon tumor type (50-52). Nonetheless, in many 
instances the best available chemotherapy may be identical for a variety of sarcoma types and may not provide any therapeutic benefit (53).

The role of chemotherapy in the neoadjuvant setting is controversial; however, strong rationale and emerging data favors the use of conventional multi-agent chemotherapy in high-risk STS (54). This is based on a recent randomized controlled trial comparing the role of conventional chemotherapy (anthracycline and ifosfamide) over histologically directed chemotherapy in high-risk extremity or trunk STS of the 5 most common histological subtypes (myxoid liposarcoma, undifferentiated pleomorphic sarcoma, synovial sarcoma, leiomyosarcoma, and malignant peripheral nerve sheath tumor). The trial was stopped early after interim analysis showed a significant benefit in favor of conventional chemotherapy over histologically directed chemotherapy (55). The use of neoadjuvant chemotherapy ultimately should be decided in a multidisciplinary tumor board based on individual patient risk and ability to tolerate chemotherapy. Surgery remains the only curativetreatment and central pillar of treatment the paradigm, but chemotherapy may have the potential to downsize the tumor leading to limb or organ sparing surgery besides offering theoretical advantages of limiting micrometastatic disease and in-vivo assessment to chemotherapy (56).

Adjuvant chemotherapy has not been universally adopted except for osteosarcoma and Ewing sarcoma. The largest meta-analysis so far including 1,953 patients from 18 trials has shown a significant benefit in terms of local recurrence [odds ratio $(\mathrm{OR})=0.73 ; 95 \% \mathrm{CI}, 0.56-0.94 ; \mathrm{P}=0.02$ ], distant and overall recurrence $(\mathrm{OR}=0.67 ; 95 \% \mathrm{CI}, 0.56-0.82$; $\mathrm{P}=0.0001)$ in favor of chemotherapy with doxorubicin and ifosfamide (40). The impact of chemotherapy on survival, however, is modest. Based upon the meta-analytic examination, a benefit is only observed with doxirubicin and ifosfamide with an absolute risk reduction of death from $46 \%$ to $40 \%(\mathrm{P}<0.05)$. This has been estimated to translate into a number needed to treat of 17 to benefit one patient (40). Therefore, adjuvant chemotherapy is reasonable especially for patients with high-risk STS who have not received neoadjuvant chemotherapy. Again, the decision to give chemotherapy should be individualized and made in a multidisciplinary tumor board. Furthermore, patients should be made aware of the limited demonstrated benefit in overall survival.

Molecular analyses to identify critical mutations that lead to the development of various sarcomas and the resultant use of targeted therapies have begun to improve outcomes for some patients. Today, select mechanistic breakthroughs and targeted therapies for specific sarcomas has resulted in dramatically different outcomes for certain specific tumor types. GIST, for example, has demonstrated a radical transformation in patient outcomes following the recognition that type III tyrosine kinase receptor mutations, particularly of cKit, are present in most GIST tumors and targeted therapies can be highly effective in their management (57-59).

Phase II studies have begun to identify new therapies for specific sarcoma subtypes. This includes better therapies to treat different liposarcoma subtypes (including myxoliposarcoma) $(60,61)$. However, due to the rarity of STS and its many subtypes, it is difficult to have enough power to evaluate chemotherapeutic response to individual subtypes, causing them to frequently be lumped together. For unresectable advanced STS, chemotherapy with a palliative intent (decrease symptoms and improve survival and quality of life) is usual treatment. Therefore, current the mainstay chemotherapeutic option for most STS remains an anthracycline usually doxorubicin, with or without an alkylating agent, usually ifosfamide with mesna or olaratumab (anti-PDGFR $\alpha$ antibody) (62-64). Combination chemotherapy generally offers a higher response rate, however, responses are short-lived and OS benefit has not been clearly demonstrated for any combination in a phase III randomized clinical trial. A phase II trial combining olaratumab with doxorubicin has recently shown significant benefit in median PFS (6.6 vs. 4.1 months; $\mathrm{HR}=0.67 ; 95 \% \mathrm{CI}, 0.44-1.02 ; \mathrm{P}=0.05)$ as well as median OS (26.5 vs. 14.7 months; HR $=0.46$; 95\% CI, $0.30-0.71 ; \mathrm{P}=0.0003)$ and lead to an accelerated approval of olaratumab, but phase III data is awaited. Notably, a recent meta-analysis of multi-agent chemotherapy in advanced STS including 22 trials (phase II and III) from 1974 to 2016 showed that multi-agent chemotherapy was associated with significant improvement in OS (HR =0.79; 95\% CI, 0.65-0.97; $\mathrm{P}=0.02$ ) and modest improvement in PFS (HR $=0.86$; 95\% CI, $0.73-$ $1.00 ; \mathrm{P}=0.05)$. However, subgroup analysis by anthracycline containing $v s$. non-anthracycline containing chemotherapy showed no difference in OS or PFS (65).

Alternative therapies for anthracycline-insensitive subtypes: pigmented villonodular tenosynovitis, tenosynovial giant cell tumor, dermatofibrosarcoma protuberans, neoplasm with perivascular epithelioid cell differentiation, endothelioid hemangioendothelioma, solitary fibrous tumor, alveolar soft parts sarcoma, and extraskeletal myxoid chondrosarcoma with EWSR1-NR4A3 fusion, are summarized in Table 1 (66-75). These therapies 
Table 1 Summary of current systemic treatment options for patients with STS

\begin{tabular}{|c|c|c|c|}
\hline STS type & First line & Second line & Third line \\
\hline PVNS/TGCT & Imatinib & Pazopanib & Clinical trial \\
\hline DFSP & Imatinib & Pazopanib & Clinical trial \\
\hline PEComa & Sirolimus & Pazopanib & Clinical trial \\
\hline SFT/hemangiopericytoma & Sunitinib/pazopanib & Clinical trial & \\
\hline ASPS & Sunitinib/pazopanib & Clinical trial & \\
\hline clear cell sarcoma & Sunitinib/pazopanib & Clinical trial & \\
\hline $\mathrm{EMC}^{\mathrm{a}}$ & Sunitinib/pazopanib & Trabectedin & Clinical trial \\
\hline UPS/MFH & Doxorubicin +/- olaratumab/ifosfamide & Gemcitabine + docetaxel & Clinical trial \\
\hline MPNST & Doxorubicin +/- olaratumab/ifosfamide & Pazopanib & Clinical trial \\
\hline GIST & Imatinib & Sorafenib & Regorafenib/clinical trial \\
\hline Other & Doxorubicin +/- olaratumab/ifosfamide & Pazopanib/trabectedin ${ }^{\mathrm{b}}$ & Clinical trial \\
\hline
\end{tabular}

a: with EWSR1-NR4A3 fusion; ${ }^{\text {b: }}$ for translocation-associated STS. PVNS, pigmented villonodular tenosynovitis; TGCT, tenosynovial giant cell tumor; DFSP, dermatofibrosarcoma protuberans; PEComa, neoplasm with perivascular epithelioid cell differentiation; EHE, endothelioid hemangioendothelioma; SFT, solitary fibrous tumor; ASPS, alveolar soft parts sarcoma; EMC, extraskeletal myxoid chondrosarcoma; UPS, undifferentiated pleomorphic sarcoma; MFH, malignant fibrous histiocytoma; MPNST, malignant peripheral nerve sheath tumor; GIST, gastrointestinal stromal tumor.

can be used neoadjuvantly to downsize tumors, adjuvantly, or to control unresectable disease. Unfortunately, these therapies have modest benefit. For example, in the case of doxorubicin plus olaratumab, progression free survival is increased by 2.5 months $(4,64)$. Targeted therapies, such as those used for GIST are needed for other STS subtypes. Currently next generation sequencing is being implemented to discover potential drug targets (76).

\section{Prognostic factors}

The most important prognostic factors are histologic grade, tumor size, and stage at the time of diagnosis. Local control is the key to a favorable outcome. Improved outcomes for patients with head and neck or extremity sarcomas are largely due to increased likelihood for earlier diagnosis, the ability to more easily excise many extremity tumors with negative margins, and a better ability to provide adjuvant radiotherapy at higher doses $(3,12,14,77)$. A postoperative nomogram can be used to predict 12-year mortality (78).

\section{Conclusions}

STS is a rare, but increasingly common malignancy. Early diagnosis and referral to a specialized center are crucial for a favorable outcome due to the availability of expertise, multimodality treatment, and access to clinical trials. While advances in adjuvant therapies are being made, complete surgical excision remains the mainstay of therapy. Systemic therapies for STS subtypes other than GIST are limited in benefit; however, successful targeted therapies for GIST provide hope for novel therapies being developed.

\section{Acknowledgements}

None.

\section{Footnote}

Conflicts of Interest: The authors have no conflicts of interest to declare. 


\section{References}

1. Ng VY, Scharschmidt TJ, Mayerson JL, et al. Incidence and survival in sarcoma in the United States: a focus on musculoskeletal lesions. Anticancer Res 2013;33:2597-604.

2. Siegel RL, Miller KD, Jemal A. Cancer statistics, 2018. CA Cancer J Clin 2018;68:7-30.

3. Zagars GK, Ballo MT, Pisters PW, et al. Prognostic factors for patients with localized soft-tissue sarcoma treated with conservation surgery and radiation therapy: an analysis of 1225 patients. Cancer 2003;97:2530-43.

4. Adjuvant chemotherapy for localised resectable soft tissue sarcoma in adults. Sarcoma Meta-analysis Collaboration (SMAC). Cochrane Database Syst Rev 2000;(2):CD001419.

5. Jawad MU, Cheung MC, Clarke J, et al. Osteosarcoma: improvement in survival limited to high-grade patients only. J Cancer Res Clin Oncol 2011;137:597-607.

6. Blanke CD, Demetri GD, von Mehren M, et al. Longterm results from a randomized phase II trial of standardversus higher-dose imatinib mesylate for patients with unresectable or metastatic gastrointestinal stromal tumors expressing KIT. J Clin Oncol 2008;26:620-5.

7. Verweij J, van Oosterom A, Blay JY, et al. Imatinib mesylate (STI-571 Glivec, Gleevec) is an active agent for gastrointestinal stromal tumours, but does not yield responses in other soft-tissue sarcomas that are unselected for a molecular target. Results from an EORTC Soft Tissue and Bone Sarcoma Group phase II study. Eur J Cancer 2003;39:2006-11.

8. Potter BO, Sturgis EM. Sarcomas of the head and neck. Surg Oncol Clin N Am 2003;12:379-417.

9. Liles JS, Tzeng CW, Short JJ, et al. Retroperitoneal and intra-abdominal sarcoma. Curr Probl Surg 2009;46:445-503.

10. Porter GA, Baxter NN, Pisters PW. Retroperitoneal sarcoma: a population-based analysis of epidemiology, surgery, and radiotherapy. Cancer 2006;106:1610-6.

11. Gutierrez JC, Perez EA, Franceschi D, et al. Outcomes for soft-tissue sarcoma in 8249 cases from a large state cancer registry. J Surg Res 2007;141:105-14.

12. Koniaris LG, Sola JE. Prognostication for trunk and retroperitoneal sarcomas. Ann Surg 2010;252:201; author reply -2 .

13. Lawrence W Jr, Donegan WL, Natarajan N, et al. Adult soft tissue sarcomas. A pattern of care survey of the American College of Surgeons. Ann Surg 1987;205:349-59.

14. Kraus DH, Dubner S, Harrison LB, et al. Prognostic factors for recurrence and survival in head and neck soft tissue sarcomas. Cancer 1994;74:697-702.

15. Aisen AM, Martel W, Braunstein EM, et al. MRI and CT evaluation of primary bone and soft-tissue tumors. AJR Am J Roentgenol 1986;146:749-56.

16. Strauss DC, Qureshi YA, Hayes AJ, et al. The role of core needle biopsy in the diagnosis of suspected soft tissue tumours. J Surg Oncol 2010;102:523-9.

17. Sundaram M, McGuire MH, Herbold DR. Magnetic resonance imaging of soft tissue masses: an evaluation of fifty-three histologically proven tumors. Magn Reson Imaging 1988;6:237-48.

18. Lahat G, Madewell JE, Anaya DA, et al. Computed tomography scan-driven selection of treatment for retroperitoneal liposarcoma histologic subtypes. Cancer 2009;115:1081-90.

19. Berger-Richardson D, Swallow CJ. Needle tract seeding after percutaneous biopsy of sarcoma: Risk/benefit considerations. Cancer 2017;123:560-7.

20. Heslin MJ, Lewis JJ, Woodruff JM, et al. Core needle biopsy for diagnosis of extremity soft tissue sarcoma. Ann Surg Oncol 1997;4:425-31.

21. Serpell JW, Pitcher ME. Pre-operative core biopsy of softtissue tumours facilitates their surgical management. Aust N Z J Surg 1998;68:345-9.

22. Woon DT, Serpell JW. Preoperative core biopsy of soft tissue tumours facilitates their surgical management: a 10year update. ANZ J Surg 2008;78:977-81.

23. Coindre JM. Grading of soft tissue sarcomas: review and update. Arch Pathol Lab Med 2006;130:1448-53.

24. Ray-Coquard I, Ranchere-Vince D, Thiesse P, et al. Evaluation of core needle biopsy as a substitute to open biopsy in the diagnosis of soft-tissue masses. Eur J Cancer 2003;39:2021-5.

25. Singer S, Demetri GD, Baldini EH, et al. Management of soft-tissue sarcomas: an overview and update. Lancet Oncol 2000;1:75-85.

26. Bonvalot S, Raut CP, Pollock RE, et al. Technical considerations in surgery for retroperitoneal sarcomas: position paper from E-Surge, a master class in sarcoma surgery, and EORTC-STBSG. Ann Surg Oncol 2012;19:2981-91.

27. Catton CN, O'Sullivan B, Kotwall C, et al. Outcome and prognosis in retroperitoneal soft tissue sarcoma. Int J Radiat Oncol Biol Phys 1994;29:1005-10.

28. Ahlen J, Karlsson F, Wejde J, et al. Wide Surgical Margin Improves the Outcome for Patients with Gastrointestinal Stromal Tumors (GISTs). World J Surg 2018;42:2512-21.

29. Anaya DA, Lev DC, Pollock RE. The role of surgical margin status in retroperitoneal sarcoma. J Surg Oncol 
2008;98:607-10.

30. Rosenberg SA, Tepper J, Glatstein E, et al. The treatment of soft-tissue sarcomas of the extremities: prospective randomized evaluations of (1) limb-sparing surgery plus radiation therapy compared with amputation and (2) the role of adjuvant chemotherapy. Ann Surg 1982;196:305-15.

31. Kandel R, Coakley N, Werier J, et al. Surgical margins and handling of soft-tissue sarcoma in extremities: a clinical practice guideline. Curr Oncol 2013;20:e247-54.

32. Tuan J, Vitolo V, Vischioni B, et al. Radiation therapy for retroperitoneal sarcoma. Radiol Med 2014;119:790-802.

33. 32. Coindre JM, Terrier P, Bui NB, et al. Prognostic factors in adult patients with locally controlled soft tissue sarcoma. A study of 546 patients from the French Federation of Cancer Centers Sarcoma Group. J Clin Oncol 1996;14:869-77.

34. Davidge KM, Wunder J, Tomlinson G, et al. Function and health status outcomes following soft tissue reconstruction for limb preservation in extremity soft tissue sarcoma. Ann Surg Oncol 2010;17:1052-62.

35. Groundland JS, Ambler SB, Houskamp LD, et al. Surgical and Functional Outcomes After Limb-Preservation Surgery for Tumor in Pediatric Patients: A Systematic Review. JBJS Rev 2016;4.

36. Cannon CP, Ballo MT, Zagars GK, et al. Complications of combined modality treatment of primary lower extremity soft-tissue sarcomas. Cancer 2006;107:2455-61.

37. Ormsby MV, Hilaris BS, Nori D, et al. Wound complications of adjuvant radiation therapy in patients with soft-tissue sarcomas. Ann Surg 1989;210:93-9.

38. Renard AJ, Veth RP, Schreuder HW, et al. Function and complications after ablative and limb-salvage therapy in lower extremity sarcoma of bone. J Surg Oncol 2000;73:198-205.

39. Gundle KR, Gupta S, Kafchinski L, et al. An Analysis of Tumor- and Surgery-Related Factors that Contribute to Inadvertent Positive Margins Following Soft Tissue Sarcoma Resection. Ann Surg Oncol 2017;24:2137-44.

40. Pervaiz N, Colterjohn N, Farrokhyar F, et al. A systematic meta-analysis of randomized controlled trials of adjuvant chemotherapy for localized resectable soft-tissue sarcoma. Cancer 2008;113:573-81.

41. Gronchi A, Casali PG, Fiore M, et al. Retroperitoneal soft tissue sarcomas: patterns of recurrence in 167 patients treated at a single institution. Cancer 2004;100:2448-55.

42. Russo P, Kim Y, Ravindran S, et al. Nephrectomy during operative management of retroperitoneal sarcoma. Ann Surg Oncol 1997;4:421-4.

43. Gutierrez JC, Perez EA, Moffat FL, et al. Should soft tissue sarcomas be treated at high-volume centers? An analysis of 4205 patients. Ann Surg 2007;245:952-8.

44. Bhangu AA, Beard JA, Grimer RJ. Should Soft Tissue Sarcomas be Treated at a Specialist Centre? Sarcoma 2004;8:1-6.

45. Gustafson P, Dreinhofer KE, Rydholm A. Soft tissue sarcoma should be treated at a tumor center. A comparison of quality of surgery in 375 patients. Acta Orthop Scand 1994;65:47-50.

46. Schwartz A, Rebecca A, Smith A, et al. Risk factors for significant wound complications following wide resection of extremity soft tissue sarcomas. Clin Orthop Relat Res 2013;471:3612-7.

47. Spera LJ, Danforth RM, Hadad I. Incisions and reconstruction approaches for large sarcoma. Transl Gastroenterol Hepatol 2018;3:86.

48. Williard WC, Hajdu SI, Casper ES, et al. Comparison of amputation with limb-sparing operations for adult soft tissue sarcoma of the extremity. Ann Surg 1992;215:269-75.

49. Davis AM, O'Sullivan B, Turcotte R, et al. Late radiation morbidity following randomization to preoperative versus postoperative radiotherapy in extremity soft tissue sarcoma. Radiother Oncol 2005;75:48-53.

50. Eriksson M. Histology-driven chemotherapy of soft-tissue sarcoma. Ann Oncol 2010;21:270-6.

51. Barretina J, Taylor BS, Banerji S, et al. Subtype-specific genomic alterations define new targets for soft-tissue sarcoma therapy. Nat Genet 2010;42:715-21.

52. Frezza AM, Stacchiotti S, Gronchi A. Systemic treatment in advanced soft tissue sarcoma: what is standard, what is new. BMC Med 2017;15:109.

53. Ratan R, Patel SR. Chemotherapy for soft tissue sarcoma. Cancer 2016;122:2952-60.

54. Gronchi A, Jones RL. The Value of Neoadjuvant Chemotherapy in Localized High-Risk Soft-Tissue Sarcoma of the Extremities and Trunk. JAMA Oncol 2018;4:1167-8.

55. Gronchi A, Ferrari S, Quagliuolo V, et al. Histotypetailored neoadjuvant chemotherapy versus standard chemotherapy in patients with high-risk soft-tissue sarcomas (ISG-STS 1001): an international, open-label, randomised, controlled, phase 3, multicentre trial. Lancet Oncol 2017;18:812-22.

56. Baldini EH, Le Cesne A, Trent JC. Neoadjuvant Chemotherapy, Concurrent Chemoradiation, and Adjuvant Chemotherapy for High-Risk Extremity Soft Tissue Sarcoma. Am Soc Clin Oncol Educ Book 2018;(38):910-5.

57. Boikos SA, Pappo AS, Killian JK, et al. Molecular Subtypes of KIT/PDGFRA Wild-Type Gastrointestinal Stromal 
Tumors: A Report From the National Institutes of Health Gastrointestinal Stromal Tumor Clinic. JAMA Oncol 2016;2:922-8.

58. DeMatteo RP, Ballman KV, Antonescu CR, et al. Longterm results of adjuvant imatinib mesylate in localized, high-risk, primary gastrointestinal stromal tumor: ACOSOG Z9000 (Alliance) intergroup phase 2 trial. Ann Surg 2013;258:422-9.

59. Dematteo RP, Ballman KV, Antonescu CR, et al. Adjuvant imatinib mesylate after resection of localised, primary gastrointestinal stromal tumour: a randomised, doubleblind, placebo-controlled trial. Lancet 2009;373:1097-104.

60. Ray-Coquard I, Blay JY, Italiano A, et al. Effect of the MDM2 antagonist RG7112 on the P53 pathway in patients with MDM2-amplified, well-differentiated or dedifferentiated liposarcoma: an exploratory proof-ofmechanism study. Lancet Oncol 2012;13:1133-40.

61. Dickson MA, Tap WD, Keohan ML, et al. Phase II trial of the CDK4 inhibitor PD0332991 in patients with advanced CDK4-amplified well-differentiated or dedifferentiated liposarcoma. J Clin Oncol 2013;31:2024-8.

62. Edmonson JH, Ryan LM, Blum RH, et al. Randomized comparison of doxorubicin alone versus ifosfamide plus doxorubicin or mitomycin, doxorubicin, and cisplatin against advanced soft tissue sarcomas. J Clin Oncol 1993;11:1269-75.

63. Santoro A, Tursz T, Mouridsen H, et al. Doxorubicin versus CYVADIC versus doxorubicin plus ifosfamide in first-line treatment of advanced soft tissue sarcomas: a randomized study of the European Organization for Research and Treatment of Cancer Soft Tissue and Bone Sarcoma Group. J Clin Oncol 1995;13:1537-45.

64. Tap WD, Jones RL, Van Tine BA, et al. Olaratumab and doxorubicin versus doxorubicin alone for treatment of softtissue sarcoma: an open-label phase $1 \mathrm{~b}$ and randomised phase 2 trial. Lancet 2016;388:488-97.

65. Zer A, Prince RM, Amir E, et al. Multi-agent chemotherapy in advanced soft tissue sarcoma (STS) - A systematic review and meta-analysis. Cancer Treat Rev 2018;63:71-8.

66. Blay JY, Italiano A, Ray-Coquard I, et al. Long-term outcome and effect of maintenance therapy in patients with advanced sarcoma treated with trabectedin: an analysis of 181 patients of the French ATU compassionate use program. BMC Cancer 2013;13:64.

67. Garcia-Carbonero R, Supko JG, Manola J, et al. Phase II and pharmacokinetic study of ecteinascidin 743 in patients with progressive sarcomas of soft tissues refractory to chemotherapy. J Clin Oncol 2004;22:1480-90.

68. Sleijfer S, Ray-Coquard I, Papai Z, et al. Pazopanib, a multikinase angiogenesis inhibitor, in patients with relapsed or refractory advanced soft tissue sarcoma: a phase II study from the European organisation for research and treatment of cancer-soft tissue and bone sarcoma group (EORTC study 62043). J Clin Oncol 2009;27:3126-32.

69. Wagner AJ, Malinowska-Kolodziej I, Morgan JA, et al. Clinical activity of mTOR inhibition with sirolimus in malignant perivascular epithelioid cell tumors: targeting the pathogenic activation of mTORC1 in tumors. J Clin Oncol 2010;28:835-40.

70. Bissler JJ, McCormack FX, Young LR, et al. Sirolimus for angiomyolipoma in tuberous sclerosis complex or lymphangioleiomyomatosis. N Engl J Med 2008;358:140-51.

71. Dickson MA, Schwartz GK, Antonescu CR, et al. Extrarenal perivascular epithelioid cell tumors (PEComas) respond to mTOR inhibition: clinical and molecular correlates. Int J Cancer 2013;132:1711-7.

72. Stacchiotti S, Provenzano S, Dagrada G, et al. Sirolimus in advanced epithelioid hemangioendothelioma: a retrospective case-series analysis from the italian rare cancer network database. Ann Surg Oncol 2016;23:2735-44.

73. George S, Merriam P, Maki RG, et al. Multicenter phase II trial of sunitinib in the treatment of nongastrointestinal stromal tumor sarcomas. J Clin Oncol 2009;27:3154-60.

74. Stacchiotti S, Grosso F, Negri T, et al. Tumor response to sunitinib malate observed in clear-cell sarcoma. Ann Oncol 2010;21:1130-1.

75. von Mehren M, Rankin C, Goldblum JR, et al. Phase 2 Southwest Oncology Group-directed intergroup trial (S0505) of sorafenib in advanced soft tissue sarcomas. Cancer 2012;118:770-6.

76. Lewin J, Garg S, Lau BY, et al. Identifying actionable variants using next generation sequencing in patients with a historical diagnosis of undifferentiated pleomorphic sarcoma. Int J Cancer 2018;142:57-65.

77. Maki RG, Moraco N, Antonescu CR, et al. Toward better soft tissue sarcoma staging: building on american joint committee on cancer staging systems versions 6 and 7. Ann Surg Oncol 2013;20:3377-83.

78. Kattan MW, Leung DH, Brennan MF. Postoperative nomogram for 12-year sarcoma-specific death. J Clin Oncol 2002;20:791-6.

doi: $10.21037 / \operatorname{tgh} .2018 .10 .12$

Cite this article as: Milgrom DP, Sehdev A, Kays JK, Koniaris LG. Integrating therapies for surgical adult soft tissue sarcoma patients. Transl Gastroenterol Hepatol 2018;3:88. 